\title{
Study protocol: systematic review and meta-analysis of randomized controlled trials in first-line treatment of squamous non-small cell lung cancer
}

Amy M DeLozier', Jacqueline Brown², Fanni Natanegara', Luping Zhao ${ }^{1}$, Zhanglin Lin Cui ', Stephen L Able', Lee Bowman ${ }^{1}$, Joseph Treat $^{1}$ and Lisa M Hess ${ }^{1 *}$

\begin{abstract}
Background: There is a high unmet need for effective treatments for patients with squamous non-small cell lung cancer (NSCLC). Eli Lilly and Company is conducting a phase III, randomized, multicenter, open-label study of gemcitabine plus cisplatin plus necitumumab $(\mathrm{GC}+\mathrm{N})$ versus gemcitabine plus cisplatin (GC) for the first-line treatment of patients with stage IV squamous NSCLC. Given GC is not the only treatment commonly used for the treatment of squamous NSCLC, this study was designed to compare the survival, toxicity, and quality of life outcomes of current treatment strategies for squamous NSCLC in the first-line setting.

Methods/Design: A systematic review and meta-analysis (including indirect comparisons) of treatments used in squamous NSCLC will be conducted to assess the clinical efficacy (overall and progression-free survival), health-related quality of life (HRQoL), and safety (grade 3-4 toxicity) of GC + N compared to other treatments used in squamous NSCLC. PRISMA (Preferred Reporting Items for Systematic Reviews and Meta-Analyses) guidelines will be followed for all aspects of this study. A systematic literature review will be conducted to identify randomized controlled trials evaluating chemotherapy treatment in first-line NSCLC. Eligible articles will be restricted to randomized controlled trials (RCTs) among chemotherapy-naïve advanced NSCLC cancer patients that report outcome data (survival, toxicity, or quality of life) for patients with squamous histology. Following data extraction and validation, data consistency and study heterogeneity will be assessed. A network meta-analysis will be conducted based on the available hazard ratios for overall and progression-free survival, odds ratios for published toxicity data, and mean difference of HRQoL scales. Sensitivity analyses will be conducted.
\end{abstract}

Discussion: This is a presentation of the study protocol only. Results and conclusions are pending completion of this study.

Systematic review registration: PROSPERO CRD42014008968

Keywords: Non-small cell lung cancer, Chemotherapy, Non-squamous, Cancer, Meta-analysis, Network meta-analysis

\footnotetext{
* Correspondence: hess_lisa_m@lilly.com

'Eli Lilly and Company, Indianapolis, IN, USA

Full list of author information is available at the end of the article
} 


\section{Background}

Lung cancer is the leading cause of cancer-related deaths worldwide, accounting for 1.3 million deaths annually [1]. It is defined as cancer that forms in the tissues of the lung, usually in the cells lining air passages, and is divided into two main subtypes: small cell lung cancer (SCLC) and non-small cell lung cancer (NSCLC). NSCLC is the predominant subtype form and accounts for about $85 \%$ of all lung cancers [2]; it is further divided by cell histology into adenocarcinoma, squamous cell carcinoma, and large-cell carcinoma, with adenocarcinoma the currently predominant histology. Although the overall age-adjusted incidence rates for lung cancer are declining in many developed nations, lung cancer remains the leading cause of cancerrelated deaths worldwide with an overall 5-year survival rate of about 15\% [3], resulting in a significant disease burden worldwide.

The treatment of lung cancer is based on the type and stage of tumor, as well as the patient's general medical condition. For patients diagnosed with early stage disease (i.e., stages I and II), surgery offers the best option for survival and cure. Adjuvant chemotherapy is increasingly used in those with stage II disease and occasionally for those with stage IB, depending on the size of the tumor. For those with stage III lung cancer, chemoradiotherapy alone or in addition to surgery is used to treat patients; however, while treatment is administered with a curative intent, the 5-year survival for patients with regional disease is approximately $26 \%$, which decreases to $3.9 \%$ for patients with metastatic disease [3]. Treatment for patients with advanced disease tends to be palliative, although extension in survival may be achieved. The standard first-line drug treatments for advanced NSCLC, neoadjuvant, adjuvant, or chemoradiotherapy, are generally based on the combination of a second- or third-generation cytotoxic drug with a platinum agent (cisplatin or carboplatin).

There are many drug therapies available for treatment of NSCLC; however, not all current therapies are suitable for use in tumors of all histologies. The results of clinical trials have indicated that drugs such as pemetrexed have greater efficacy among patients with adenocarcinoma than those with other NSCLC histologies (e.g., squamous cell carcinoma) [4]. Other newer agents, such as bevacizumab, are indicated for adenocarcinoma because of higher toxicities observed in patients with squamous histology [5]. Drugs such as erlotinib and gefitinib are not restricted by histology, but have greater efficacy among patients with epidermal growth factor receptor (EGFR) mutations [6,7]. The frequency of EGFR mutations in patients with squamous cell carcinoma, as opposed to those with adenocarcinoma, is very low [8]. Therefore, histology-specific treatment options are limited for patients with squamous cell carcinoma, which accounts for about $25 \%$ of all non-small cell lung cancers [9].

There is thus a high unmet need for effective treatments for patients with squamous NSCLC, as disease burden is large and there is currently a lack of targeted drug therapies for NSCLC squamous cell tumors. Eli Lilly and Company is currently developing necitumumab as a first-line treatment in patients with stage IV squamous NSCLC. The current phase III study (ClinicalTrials.gov identifier: NCT00981058) is a randomized, multicenter, open-label study of gemcitabine-cisplatin chemotherapy plus necitumumab $(\mathrm{GC}+\mathrm{N})$ versus gemcitabine-cisplatin (GC) chemotherapy alone in first-line treatment of patients with stage IV squamous NSCLC. The target patient population for this trial is comprised of male and female patients with histologically or cytologically confirmed, advanced squamous NSCLC, previously untreated for metastatic disease.

The purpose of this systematic literature review and meta-analysis is to compare survival, toxicity, and quality of life outcomes of current treatment strategies with necitumumab among patients with squamous NSCLC.

\section{Methods/Design}

This systematic literature review and meta-analysis (including indirect comparisons) will be conducted of treatments used in squamous NSCLC to assess the clinical efficacy, quality of life, and safety of GC $+\mathrm{N}$ compared to other treatments used in squamous NSCLC. To complete this objective, the following specific aims will be pursued:

1. To conduct a systematic literature review of randomized trials of all relevant treatments used for the first-line treatment of advanced squamous NSCLC;

2. To extract relevant data from the relevant published literature;

3. To perform indirect and direct comparisons of $\mathrm{GC}+\mathrm{N}$ to all identified comparators for the following outcomes:

3.1 Overall survival;

3.2 Progression-free survival;

3.3 Toxicity; and

3.4 Quality of life

\section{Search strategy}

Searches will be conducted in PubMed, Ovid/MEDLINE, and Embase using free text and controlled vocabulary terms (MeSH). Studies published prior to 1995 will be excluded as NSCLC histology was not clearly differentiated at that time. Studies not published in English will be excluded. Comparisons will be made across all regimens and not just limited to "add-on" therapies. Tables 1 , 
Table 1 PubMed search strategy

\begin{tabular}{|c|c|c|c|}
\hline \multicolumn{4}{|c|}{ PubMed search } \\
\hline Category & Search & Query & Items found \\
\hline Disease terms & $\# 1$ & "carcinoma, non small cell lung/drug therapy" [MeSH Terms] & 11,135 \\
\hline \multirow[t]{16}{*}{ Design terms } & $\# 2$ & Randomized Controlled Trials as Topic [MeSH Major Topic] & 12,361 \\
\hline & \#3 & "randomized controlled trials as topic" [MeSH Terms] & 85,095 \\
\hline & \#4 & Random Allocation [MeSH Terms] & 76,843 \\
\hline & $\# 5$ & double blind method [MeSH Terms] & 118,616 \\
\hline & \#6 & "controlled clinical trial" [Publication Type] & 85,642 \\
\hline & \#7 & "randomized controlled trial" [Publication Type] & 344,749 \\
\hline & $\# 8$ & "clinical trials as topic" [MeSH Terms] & 263,513 \\
\hline & \#9 & "clinical trial" [Publication Type] & 709,361 \\
\hline & $\# 10$ & $((\# 2$ or $\# 3$ or $(\# 4$ and $(\# 5$ or $\# 8$ or \#9)) or \#6 or \#7)) & 509,729 \\
\hline & $\# 11$ & ((randomization and control and clinical and trial)) & 10,468 \\
\hline & $\# 12$ & $((($ randomised and control and clinical and trial) or (randomized and control and clinical and trial))) & 108,134 \\
\hline & $\# 13$ & $\left(\left(\left(\left(\right.\right.\right.\right.$ double or single or triple or treble) and (blind* or mask*) and $\left(\right.$ random $\left.\left.\left.\left.^{*}\right)\right)\right)\right)$ & 136,554 \\
\hline & $\# 14$ & $((($ random and allocat*) and control* and trial $))$ & 4,775 \\
\hline & \#15 & (\#12 or \#13 or \#14) & 214,899 \\
\hline & $\# 16$ & (\#10 or \#15) & 527,440 \\
\hline & \#17 & (\#1 AND \#16) & 2,065 \\
\hline \multirow[t]{7}{*}{ Exclusion terms } & $\# 18$ & Case report [Title/Abstract] & 195,029 \\
\hline & $\# 19$ & Review [Publication Type] & $1,765,829$ \\
\hline & \#20 & Letter [Publication Type] & 794,012 \\
\hline & \#21 & "systematic review" [Title/Abstract] & 39,341 \\
\hline & \#22 & "clinical review" [Title/Abstract] & 3,144 \\
\hline & \#23 & (\#18 OR \#19 OR \#20 OR \#21 OR \#22) & $2,734,788$ \\
\hline & \#24 & (\#17 NOT \#23) & 1,579 \\
\hline Year and language terms & \#25 & ((\#24) AND ("1995" [Date - Publication]: "2013" [Date - Publication])) AND English [Language] & 1,217 \\
\hline
\end{tabular}

2, and 3 detail the specific search strategies for PubMed, Ovid, and Embase, respectively.

The following is a list of the conference databases that will be searched:

- American Association for Cancer Research, AACR

- American College of Radiation Oncology

- American Society for Radiation Oncology, ASTRO

- American Society of Clinical Oncology, ASCO

- Asia Pacific Lung Cancer Conference, APLCC

- Asia Pacific Oncology Summit, APOS

- Asian Oncology Summit, AOS

- Atualizacoes em Oncologia

- Australian Lung Cancer Conference, ALCC

- Austrian Society of Haematology and Oncology, ASHO

- The Association for Cancer Surgery, BASO

- Biennial Congress of the European Association for Cancer Research, EACR
- British Thoracic Oncology Group Conference, BTOG

- Clinical Oncology Society of Australia, COSA

- Cancer Symposium of the Society of Surgical Oncology, CSSSO

- Chicago Supportive Oncology Conference, CSOC

- Clinical Interventional Oncology, CIO

- Congres National de la Societe Francaise de Radiotherapie Oncologique, SFRO

- Congress of the European Society for Medical Oncology, ESMO

- Congress of the European Society of Surgical Oncology, ESSO

- Congress of the International Society of Oncology and Biomarkers, ISOBM

- Educational Cancer Convention Lugano of the European School of Oncology, ECCLU

- European Lung Cancer Conference, ELCC

- European Multidisciplinary Cancer Congress 
Table 2 Embase search strategy

\begin{tabular}{|c|c|c|c|}
\hline \multicolumn{4}{|c|}{ Embase search } \\
\hline Category & Search & Query & Hits \\
\hline \multirow[t]{14}{*}{ Design terms } & $\# 1$ & "randomized controlled trial (topic)"/exp & 37,931 \\
\hline & $\# 2$ & "randomized controlled trial"/exp & 337,523 \\
\hline & \#3 & "randomization"/exp & 61,698 \\
\hline & \#4 & "double blind procedure"/exp & 115,032 \\
\hline & \#5 & [controlled clinical trial]/lim & 511,199 \\
\hline & \#6 & [randomized controlled trial]/lim & 337,523 \\
\hline & \#7 & "clinical trial"/exp & 961,450 \\
\hline & \#8 & "clinical trial (topic)"/exp & 73,222 \\
\hline & \#9 & \#1 OR \#2 OR \#3 OR \#4 OR \#5 OR \#6 & $1,088,520$ \\
\hline & $\# 10$ & singl*: ab,ti OR doubl*: ab,ti OR treb*: ab,ti OR tripl*: ab,ti AND (blind*: ab,ti OR mask*: ab,ti) & 174,394 \\
\hline & $\# 11$ & "placebo"/exp & 236,244 \\
\hline & $\# 12$ & $\begin{array}{l}\text { random* AND (clinical OR control*) AND trial OR (placebo* AND } \\
\text { ("randomly allocated" OR (allocated AND random*))) }\end{array}$ & 504,649 \\
\hline & $\# 13$ & (\#7 OR \#8) AND (\#10 OR \#11 OR \#12) & 513,722 \\
\hline & $\# 14$ & \#9 OR \#13 & 705,098 \\
\hline \multirow[t]{10}{*}{ Exclusion terms } & $\# 15$ & [conference review]/lim & 3,863 \\
\hline & \#16 & "case report":ab,ti & 256,868 \\
\hline & $\# 17$ & [review]/lim & $2,026,389$ \\
\hline & $\# 18$ & [letter]/lim & 827,115 \\
\hline & $\# 19$ & "phase 1 clinical trial"/exp & 24,619 \\
\hline & \#20 & [short survey]/lim OR "historical article": ab,ti & 514,714 \\
\hline & \#21 & "systematic review": ab,ti & 78,920 \\
\hline & \#22 & "clinical review": ab,ti & 3,904 \\
\hline & \#23 & \#15 OR \#16 OR \#17 OR \#18 OR \#19 OR \#20 OR \#21 OR \#22 & $3,628,070$ \\
\hline & \#24 & \#14 NOT \#23 & 424,301 \\
\hline \multirow[t]{9}{*}{ Rx terms } & \#25 & "drug therapy"/exp/mj & 574,153 \\
\hline & \#26 & "treatment response"/exp/mj & 2,763 \\
\hline & \#27 & "treatment outcome"/exp/mj & 28,936 \\
\hline & \#28 & "drug efficacy"/exp/mj & 153,753 \\
\hline & \#29 & "outcome assessment"/exp/mj & 9,603 \\
\hline & \#30 & $\begin{array}{l}\text { chemothera* OR ("drug"/exp/mj AND thera*) OR antineoplastic* OR palliat* OR standar* NEAR/2 } \\
\text { care OR support* NEAR/2 care OR "best supportive care" OR best?support* NEXT/2 care }\end{array}$ & $1,895,030$ \\
\hline & \#31 & "radiotherapy"/exp & 367,367 \\
\hline & \#32 & \#25 OR \#26 OR \#27 OR \#28 OR \#29 OR \#30 OR \#31 & $2,609,134$ \\
\hline & \#33 & \#23 AND \#31 & 88,937 \\
\hline \multirow[t]{9}{*}{ Disease terms } & \#34 & ((lung\$ OR pulmon\$) NEAR/5 (adenocarcinom\$ OR squamous OR "large cell" OR "non-small cell")): ab,ti & 44,817 \\
\hline & \#35 & "lung non small cell cancer"/exp & 52,027 \\
\hline & \#36 & metastatic: ab,ti & 181,820 \\
\hline & \#37 & advanced: ab,ti & 320,393 \\
\hline & \#38 & stage 3 : ab,ti & 61 \\
\hline & \#39 & "Stage 3": ab,ti & 8,708 \\
\hline & $\# 40$ & stage 4: ab,ti & 32 \\
\hline & $\# 41$ & "stage 4": ab,ti & 5,270 \\
\hline & \#42 & stage iii: ab,ti & 30 \\
\hline
\end{tabular}


Table 2 Embase search strategy (Continued)

\begin{tabular}{|c|c|c|c|}
\hline & $\# 43$ & "stage iii": ab,ti & 31,468 \\
\hline & $\# 44$ & stage iv: ab,ti & 41 \\
\hline & \#45 & "stage iv": ab,ti & 20,205 \\
\hline & \#46 & "stage iii/iv": ab,ti & 6 \\
\hline & \#47 & "stage iii/iv": ab,ti & 4,552 \\
\hline & \#48 & "stage iiib/iv": ab,ti & 2 \\
\hline & \#49 & "stage iii/iva": ab,ti & 1 \\
\hline & $\# 50$ & stage* $^{*}$ iil: ab,ti & 32 \\
\hline & \#51 & stage $^{*}$ iii*: ab,ti & 49 \\
\hline & \#52 & stage $^{*}$ iv: ab,ti & 41 \\
\hline & $\# 53$ & stage $^{*} i v^{*}: a b, t i$ & 52 \\
\hline & \#54 & stage iii*: ab,ti & 47 \\
\hline & \#55 & stage iv*: ab,ti & 46 \\
\hline & \#56 & inoperable: ab,ti & 12,989 \\
\hline & \#57 & in* operable: $a b, t i$ & 13,465 \\
\hline & \#58 & unresectable: ab,ti & 15,735 \\
\hline & \#59 & non* resectable: ab,ti & 1,208 \\
\hline & $\# 60$ & late ${ }^{*}$ stage: ab,ti & 84 \\
\hline & $\# 61$ & late: ab,ti AND stage: ab,ti & 41,346 \\
\hline & $\# 62$ & metast*: ab,ti OR advance ${ }^{*}: a b, t i$ & 900,959 \\
\hline & \#63 & $\begin{array}{l}\text { relaps* OR recurr* OR unresect* OR non?resect* OR in?operable OR non?operable } \\
\text { OR un?operable OR advanc* OR metasta* OR late NEAR/2 stage }\end{array}$ & $1,895,338$ \\
\hline & $\# 64$ & \#34 OR \#35 & 61,621 \\
\hline & $\# 65$ & $\begin{array}{l}\text { \#36 OR \#37 OR \#38 OR \#39 OR \#40 OR \#41 OR \#42 OR \#43 OR \#44 OR \#45 OR \#46 OR \#47 OR \#48 OR \#49 } \\
\text { OR \#50 OR \#51 OR \#52 OR \#53 OR \#54 OR \#55 OR \#56 OR \#57 OR \#58 OR \#59 OR \#60 OR \#61 OR \#62 OR \#63 }\end{array}$ & $1,943,775$ \\
\hline & \#66 & \#64 AND \#65 & 33,907 \\
\hline & $\# 67$ & \#33 AND \#66 & 2,689 \\
\hline Language and year & $\# 68$ & [1995-2013]/py AND [english]/lim & $12,998,680$ \\
\hline Final & $\# 69$ & \#67 AND \#68 & 2,901 \\
\hline
\end{tabular}

- European Multidisciplinary Conference in Thoracic Oncology, EMCTO

- Hematology Oncology Pharmacy Association Annual Meeting, HOPA

- International Conference and Exhibition on Cancer Science and Therapy, IMPAKT

- International Conference of the Society for Integrative Oncology

- International Lung Cancer Congress

- International Symposium on Targeted Anticancer Therapies, TAT

- Italian Society of Surgical Oncology Conference

- Medical Oncology Group of Australia, MOGA

- Oncology Platform and Poster Presentation, CSM 2009

- Scientific Association of Swiss Radiation Oncology, SASRO
- Scientific Meeting of the International Society for Biological Therapy of Cancer

- Scientific Meeting of the Society for Immunotherapy of Cancer, SITC

- Symposium of the International Society of Oncology Pharmacy Practitioners

- UK Radiation Oncology Conference

- World Conference on Interventional Oncology, WCIO

- World Congress on Cancer Science and Therapy

\section{Eligibility assessment}

To be eligible, published studies must meet the criteria outlined in Table 4. Briefly, eligible articles must report at least one of the following outcomes (overall survival, progression-free survival, quality of life, or toxicity) for patients with squamous NSCLC. Eligible articles must 
Table 3 Ovid/MEDLINE search strategy

\begin{tabular}{|c|c|c|c|}
\hline \multicolumn{4}{|c|}{ Ovid/MEDLINE search } \\
\hline Category & Search & Query & Hits \\
\hline \multirow[t]{17}{*}{ Design terms } & $\# 1$ & Randomized Controlled Trials as Topic/ & 100,690 \\
\hline & \#2 & Randomized Controlled Trial/ & 382,290 \\
\hline & \#3 & Random Allocation/ & 80,788 \\
\hline & \#4 & Double Blind Method/ & 129,303 \\
\hline & \#5 & controlled clinical trial.pt. & 88,866 \\
\hline & \#6 & randomized controlled trial.pt. & 382,290 \\
\hline & \#7 & Clinical Trial/ & 499,767 \\
\hline & \#8 & clinical trial.pt. & 499,767 \\
\hline & \#9 & Clinical Trials as Topic/ & 173,590 \\
\hline & $\# 10$ & 1 or 2 or 3 or 4 or 5 or 6 & 631,570 \\
\hline & \#11 & 7 or 8 or 9 & 602,541 \\
\hline & $\# 12$ & $(($ singl* or doubl* or treb* or tripl*) and (blind* or mask*)).ab,ti. & 145,496 \\
\hline & $\# 13$ & Placebos/ & 33,372 \\
\hline & $\# 14$ & $\begin{array}{l}((\text { random* and }(c l i n i c a l \text { or control*) and trial) or (placebo* and ("randomly allocated" or } \\
(\text { allocated and random*) )).mp. [mp = title, abstract, original title, name of substance word, } \\
\text { subject heading word, keyword heading word, protocol supplementary concept, } \\
\text { rare disease supplementary concept, unique identifier] }\end{array}$ & 457,488 \\
\hline & $\# 15$ & 12 or 13 or 14 & 513,100 \\
\hline & $\# 16$ & 11 and 15 & 264,991 \\
\hline & $\# 17$ & 10 or 16 & 645,804 \\
\hline \multirow[t]{6}{*}{ Disease terms } & $\# 18$ & ((lung* or pulmon*) and (adenocarcinom* or squamous or "large cell" or "non-small cell")).ab,ti. & 59,093 \\
\hline & $\# 19$ & Carcinoma, Non-Small-Cell Lung/ & 34,861 \\
\hline & $\# 20$ & $\begin{array}{l}\text { (metastatic or advanced or stage or "stage 3" or stage4 or "stage 4" or stagelll or "stage III" } \\
\text { or StagelV or "Stage IV" or Stage? III or "Stage ?II" or Stage?IV or "Stage ?IV" or "StagellI/IV" or } \\
\text { "Stage III/IV" or "StagellI?/IV?" or "Stage III?/IV?" or "StagellI/StagelV" or "Stage III/Stage IV" or } \\
\text { "StagellI?/StagelV?" or "Stage III?/Stage IV?" or inoperable or in?operable or unresectable or } \\
\text { non?resectable or "late?stage" or (metast* or advance*)).ab,ti. }\end{array}$ & $1,177,250$ \\
\hline & \#21 & 18 or 19 & 66,533 \\
\hline & \#22 & 20 and 21 & 34,403 \\
\hline & \#23 & 17 and 22 & 3,600 \\
\hline \multirow[t]{9}{*}{ Exclusion terms } & \#24 & case report.ab,ti. & 201,610 \\
\hline & \#25 & review.pt. & $1,893,388$ \\
\hline & \#26 & letter.pt. & 817,960 \\
\hline & $\# 27$ & Clinical Trial, Phase I.pt. & 15,867 \\
\hline & \#28 & Historical Article/ & 298,058 \\
\hline & $\# 29$ & systematic review.ab,ti. & 44,587 \\
\hline & $\# 30$ & clinical review.ab,ti. & 3,354 \\
\hline & \#31 & 24 or 25 or 26 or 27 or 28 or 29 or 30 & $3,184,956$ \\
\hline & \#32 & 23 not 31 & 2,702 \\
\hline \multirow[t]{2}{*}{ Rx terms } & \#33 & $\begin{array}{l}\text { drug therapy/ or treatment outcome/ or ("treatment" and "response").ab,ti. or } \\
\text { ("drug" and "efficacy").ab,ti. or outcome assessment/ }\end{array}$ & $1,014,086$ \\
\hline & \#34 & 32 and 33 & 1,611 \\
\hline Final & \#35 & limit 34 to yr = "1995 -Current" & 1,464 \\
\hline
\end{tabular}

report data from randomized controlled trials published since 1995. Abstracts of all potentially eligible citations will be reviewed and excluded if it can be definitively stated that no eligibility criterion is met. All other publications will be considered potentially eligible. Full-text articles of all potentially eligible citations will be obtained and 
Table 4 Eligibility criteria and screening matrix

Eligibility criteria

\begin{tabular}{|c|c|c|c|}
\hline \multirow[t]{2}{*}{ Patients } & \multicolumn{3}{|c|}{ Male or female patients with histologically or cytologicallyconfirmed squamous NSCLC } \\
\hline & \multicolumn{3}{|c|}{$\begin{array}{l}\text { Study participants must have not received chemotherapy treatment prior to first-line chemotherapy } \\
\text { for NSCLC at the time of randomization in the study }\end{array}$} \\
\hline \multirow[t]{2}{*}{ Interventions } & \multicolumn{3}{|c|}{ The study assesses a chemotherapy treatment in each of the study arms } \\
\hline & \multicolumn{3}{|c|}{ No limits are placed on the type of chemotherapy used } \\
\hline \multirow[t]{2}{*}{ Outcomes } & \multicolumn{3}{|c|}{$\begin{array}{l}\text { One or more of the following outcomes must be quantitatively reported in the publication: } \\
\text { overall survival, progression-free survival, toxicity, or quality of life }\end{array}$} \\
\hline & \multicolumn{3}{|c|}{$\begin{array}{l}\text { At least one of the required outcome variables must be reported separately for patients with } \\
\text { advanced or metastatic (stage III/IV) NSCLC that is of squamous histology }\end{array}$} \\
\hline Study design & \multicolumn{3}{|l|}{$\mathrm{RCTS}$} \\
\hline Time frame & \multicolumn{3}{|l|}{1995 to present } \\
\hline \multicolumn{4}{|c|}{ Ineligibility criteria } \\
\hline \multirow[t]{2}{*}{ Interventions } & \multicolumn{3}{|c|}{ Not first-line treatment with first-line defined as patients with no prior exposure to chemotherapy } \\
\hline & \multicolumn{3}{|c|}{ Radiation therapy in the absence of concurrent chemotherapy in any treatment group } \\
\hline Study design & \multicolumn{3}{|l|}{ Review articles, news, editorials, commentaries } \\
\hline Time frame & \multicolumn{3}{|l|}{ Publication date prior to 1995} \\
\hline \multicolumn{4}{|c|}{ Matrix for patients with "squamous histology" } \\
\hline $\begin{array}{l}\text { Squamous inclusion } \\
\text { obvious in abstract? }\end{array}$ & $\begin{array}{l}\text { Squamous results } \\
\text { obvious in abstract? }\end{array}$ & Inclusion & Comments \\
\hline Yes & Yes & Yes & \\
\hline No & Yes & Yes & \\
\hline Yes & No & Yes/No & Need full text to determine the inclusion \\
\hline No & No & Yes/No & Need full text to determine the inclusion \\
\hline $\begin{array}{l}\text { Only non-squamous inclusion } \\
\text { obvious in abstract? }\end{array}$ & $\begin{array}{l}\text { Squamous results } \\
\text { obvious in abstract? }\end{array}$ & Inclusion & Comments \\
\hline Yes & Yes & Not possible case & \\
\hline No & Yes & Yes & \\
\hline Yes & No & No & \\
\hline No & No & Yes/No & Need full text to determine the inclusion \\
\hline $\begin{array}{l}\text { Abstract mentions just } \\
\text { NSCLC as inclusion? }\end{array}$ & $\begin{array}{l}\text { Squamous results obvious } \\
\text { in abstract? }\end{array}$ & Inclusion & Comments \\
\hline Yes & Yes & Yes & \\
\hline No & Yes & Yes/No & $\begin{array}{l}\text { This may be multisite cancer study, need } \\
\text { full text to determine the inclusion }\end{array}$ \\
\hline Yes & No & Yes/No & Need full text to determine the inclusion \\
\hline No & No & Noise in the search & Need full text to determine the inclusion \\
\hline \multirow[t]{3}{*}{ Multiple cancers } & If mentions lung cancer & Yes/No & Need full text to determine the inclusion \\
\hline & If does not mention any specific tumor types & Yes/No & Need full text to determine the inclusion \\
\hline & $\begin{array}{l}\text { If only mentions breast cancer or other } \\
\text { types and does not mention lung cancer }\end{array}$ & Noise in the search & \\
\hline \multicolumn{4}{|c|}{ Matrix for "not first-line treatment" } \\
\hline Condition & Line of treatment to be considered & Inclusion & Comments \\
\hline Naïve NSCLC patients & $1 \mathrm{st}$ & Yes & \\
\hline First- or front-line treatment & $1 \mathrm{st}$ & Yes & \\
\hline Untreated NSCLC patients & $1 \mathrm{st}$ & Yes & \\
\hline $\begin{array}{l}\text { Metastatic chemo-naïve } \\
\text { NSCLC patients }\end{array}$ & $1 \mathrm{st}$ & Yes & \\
\hline Chemo-naïve NSCLC patients & $1 \mathrm{st}$ & Yes & \\
\hline
\end{tabular}


Table 4 Eligibility criteria and screening matrix (Continued)

\begin{tabular}{|c|c|c|c|}
\hline Second-line treatment & 2nd & No & \\
\hline$(\mathrm{Rx})$-resistant NSCLC patients & $2 \mathrm{nd}$ & No & \\
\hline Recurrent or progressive disease & 2nd & No & \\
\hline $\begin{array}{l}(\mathrm{Rx}) \text {-responder/non-responder } \\
\text { patients }\end{array}$ & $2 \mathrm{nd}$ & No & \\
\hline $\begin{array}{l}\text { If no clear information on line } \\
\text { of treatment }\end{array}$ & NA & Yes/No & Need full text to determine the inclusion \\
\hline
\end{tabular}

reviewed to determine final eligibility. The eligibility of both the abstracts and full-text articles will be assessed independently by two reviewers using the criteria and screening matrix presented in Table 4. If the two reviewers do not agree on the eligibility of an article, a third reviewer will serve as the tie breaker. Systematic reviews and other review articles will be scanned to ensure no eligible randomized controlled trials (RCTs) are missed.

\section{Data extraction and verification}

In a process similar to that used for assessing eligibility, two reviewers will independently extract the data elements listed in Table 5 from each eligible article. These data are extensive and it is not expected, nor is it required, that all studies will report all data fields included. However, attempts to collect as extensive of data as possible will be made to increase the potential range of sensitivity and descriptive analyses. In addition to the data extraction, two reviewers will also assess bias using the Cochrane Risk of Bias Tool and will measure study quality using the Physiotherapy Evidence Database (PEDro) scale (see the "Assessment of bias and study quality" section). Data from both reviewers will be compared. If any data element does not match, the reviewers will meet and attempt to resolve the discrepancies. In cases of non-resolution, a third reviewer will be consulted. All rules and decision criteria used in the data resolution process will be recorded for quality assurance and methodological consistency purposes. To further ensure the accuracy of the extracted data, a subset of $10 \%$ of all extracted articles will be verified by an individual not involved in the data extraction process. In cases of error detection, the full database will be reviewed to ensure accuracy.

\section{Analysis plan}

A PRISMA (Preferred Reporting Items for Systematic Reviews and Meta-Analyses) diagram will be developed based on the search strategy and eligibility assessment to show the flow of included and excluded studies. The descriptive statistics from each trial of patients with squamous cell carcinoma will be included and described. These variables will include treatment group, number of patients, mean age (standard deviation), number and percent male, number and percent with stage IV disease, overall survival, progression-free survival, toxicity, and quality of life.

A network diagram visually describing existing treatments for squamous NSCLC will be created after all eligible studies have been identified. However, some publications may not present data in a format that allows them to be included in the study despite otherwise meeting eligibility criteria (e.g., mixed populations not reported separately, mixed histologies not reported separately, mixed lines of therapy not reported separately). In the case of a disconnected network resulting from the absence of data for the appropriate patient population, authors of such articles will be contacted and asked to provide the needed data from their publications that would enable connection to the studied network.

The primary purpose of this study is to perform indirect and direct comparisons of $\mathrm{GC}+\mathrm{N}$ versus all identified comparators for overall survival (OS) and progression-free survival (PFS). Individual hazard ratios (HR) or median time-to-event (median time) and 95\% confidence intervals (90\% or $99 \%$ confidence intervals will be converted to 95\%) for overall survival will be included in the network meta-analysis using a Bayesian approach that ensures the preservation of randomization in the network [10]. The HR will be used as the primary unit of analyses to evaluate differences in effect size between treatment groups. Data for analysis will be extracted directly from the text of each eligible article, calculated from data included in the text, or extrapolated from the Kaplan-Meier plot according to the method of Parmar and colleagues [11]. Graphs and figures will be digitized using TechDig software and/or xyscan tool (Debian, Inc) if necessary, and digitized values will be extracted.

Heterogeneity will be explored by comparing the fixed and random effects models to ensure that the network has good properties. Additionally, heterogeneity will be explored by visual inspection of forest plots. The consistency assumption will be tested by examining network diagrams to identify any closed "loops" where inconsistencies can occur. When the network is complex with multiarm trials, the "node-splitting" approach defined by Dias and colleagues [12] will be used to identify 
Table 5 Variables for data extraction

\begin{tabular}{|c|c|c|}
\hline \multicolumn{3}{|c|}{ Arm-phase-period information by study arm and overall } \\
\hline Arm & $\begin{array}{l}\text { Unique arm number. Unique number for the treatment arm is } \\
\text { a grouping variable that is used to highlight which outcome is } \\
\text { in the same group of subjects }\end{array}$ & $\begin{array}{l}\text { Integer, in case of sub-analysis arm use A.a format. } \\
\text { Placebo }=0 \text {, for sub-arm } 0.1\end{array}$ \\
\hline Number of study arms & & $1,2,3$ \\
\hline \multicolumn{3}{|l|}{ Open label versus blinded } \\
\hline Phase of study & & $1,2,3$, or unknown \\
\hline Objectives & & OS, PFS, RR, TPD, etc. \\
\hline Patients randomized & Number of patients randomized to the arm & Number value \\
\hline Arm description & $\begin{array}{l}\text { Description of the treatment arm usually includes the drug } \\
\text { name, dose, and frequency }\end{array}$ & e.g., methotrexate 10 mg QW (once a week) \\
\hline Sub arm analysis & Indicates if the analysis is in a subset of study arm & $\begin{array}{l}\text { Yes, NA. Use all in case of AE or dropout data } \\
\text { is reported for the randomized trial population }\end{array}$ \\
\hline Arm comment & Comment referring to the arm & $\begin{array}{l}\text { Comment in relevance to the understating of arm } \\
\text { or NA }\end{array}$ \\
\hline Study phase & $\begin{array}{l}\text { Description of the specific phase within the overall study from } \\
\text { which the data is derived }\end{array}$ & Lead-in, active, follow-up \\
\hline Study phase description & $\begin{array}{l}\text { Qualifies the "Study Phase" field with any additional } \\
\text { information deemed necessary or helpful for that arm }\end{array}$ & e.g., open-label follow-up \\
\hline Phase duration & $\begin{array}{l}\text { Length of time of the study phase from which the data is } \\
\text { derived for the arm }\end{array}$ & Time \\
\hline Phase duration unit & Time unit for phase duration for the arm & Units \\
\hline Phase comment & Comment concerning the study phase & $\begin{array}{l}\text { Any comment that is relevant to the understanding } \\
\text { of the phase or NA }\end{array}$ \\
\hline Period & $\begin{array}{l}\text { Used if necessary to separate crossover periods within a } \\
\text { crossover trial }\end{array}$ & $\begin{array}{l}\text { If the phase has multiple periods, the number of } \\
\text { the period. Integer in sequence, or NA }\end{array}$ \\
\hline Period description & $\begin{array}{l}\text { Used to qualify the "Period" field with any additional } \\
\text { information deemed necessary or helpful }\end{array}$ & e.g., treatment $\mathrm{A}$, titration, maintenance, NA \\
\hline Period duration & $\begin{array}{l}\text { Length of time of the period in a study phase from which the } \\
\text { data is derived }\end{array}$ & Time, NA \\
\hline Period duration unit & Time unit for period duration & Units, NA \\
\hline Period comment & Comment concerning the period & $\begin{array}{l}\text { Any comment that is relevant to the understanding } \\
\text { of the period or NA }\end{array}$ \\
\hline Repository & Description & Data entry standards \\
\hline
\end{tabular}

Demographics and medical history information at baseline by study arm and overall—adjusted and unadjusted

\begin{tabular}{|c|c|c|}
\hline Age & $\begin{array}{l}\text { Mean (or median) age in years of patient population or } \\
\text { treatment arm population }\end{array}$ & $\begin{array}{l}\text { Age in years or NR if not mentioned specifically or } \\
\text { clearly in the trial }\end{array}$ \\
\hline Percent female & $\begin{array}{l}\text { Percent of females in the patient population or treatment arm } \\
\text { population }\end{array}$ & $\begin{array}{l}\text { Percent or NR if not mentioned specifically or } \\
\text { clearly in the trial }\end{array}$ \\
\hline Weight & Mean body weight of the patient or treatment arm population & $\begin{array}{l}\text { Weight in } \mathrm{kg} \text {, normalize if needed or NR if not } \\
\text { mentioned specifically or clearly in the trial }\end{array}$ \\
\hline Height & Mean height of the patient or treatment arm population & $\begin{array}{l}\text { Height in cm, normalize if needed or NR if not } \\
\text { reported }\end{array}$ \\
\hline $\mathrm{BMI}$ & Mean body mass index of the treatment arm population & $\begin{array}{l}\mathrm{BMI} \text { in } \mathrm{kg} / \mathrm{m}^{2}, \text { normalize if needed or NR if not } \\
\text { reported in the trial }\end{array}$ \\
\hline DBP & Mean (or median) diastolic blood pressure & $\mathrm{mmHg}$ \\
\hline SBP & Mean (or median) systolic blood pressure & $\mathrm{mmHg}$ \\
\hline Inclusion & $\begin{array}{l}\text { Description of treatment arm or sub-arm inclusion criteria } \\
\text { under the trial protocol }\end{array}$ & $\begin{array}{l}\text { e.g., for sub-group females only, or NR if not } \\
\text { mentioned specifically or clearly in the trial }\end{array}$ \\
\hline Exclusion & $\begin{array}{l}\text { Description of treatment arm or sub-arm exclusion criteria } \\
\text { under the trial protocol }\end{array}$ & $\begin{array}{l}\text { e.g., for sub-group exclusion of females with } \\
\text { child-bearing potential, or NR if not mentioned } \\
\text { specifically or clearly in the trial }\end{array}$ \\
\hline
\end{tabular}


Table 5 Variables for data extraction (Continued)

\begin{tabular}{ll}
\hline Ethnic white & $\begin{array}{l}\text { Percent of the ethnic population who are whites or Caucasian } \\
\text { in the trial } \\
\text { Ethnic black }\end{array}$ \\
Ethnic Hispanic & Percent of the ethnic population who are black in the trial \\
Ethnic Asian & Percent of the ethnic population who are Asian in the trial \\
Ethnic other & Percent of the ethnic population who are other in the trial \\
Primary disease & Primary disease being studied \\
Percent current smokers & Percent of the population who are current smokers \\
Percent previous smokers & Percent of the population who are previous smokers \\
Percent adenocarcinoma type & Percent subjects with NSCLC adenocarcinoma type
\end{tabular}

Percent squamous cell carcinoma type

Percent non-squamous

Percent NSCLC stage $0 / / / / 1$

Percent NSCLC stage III

Percent NSCLC stage IV

Percent NSCLC stage III/IV total

Percent ECOG status 0

Percent ECOG status 1

Percent ECOG status 0/1 total

Percent Karnofsky status $\geq 80$

Percent WHO performance status $0 / 1$

Num of metastatic lymph nodes

Percent metastatic L-node positive

Percent bone metastasis

Percent brain metastasis

Percent liver metastasis

Percent other metastasis

Percent metastatic organ sites 1 Percent subjects with one metastatic organ or site involved

Percent subjects who are lymph node positive or with metastatic lymph nodes

Percent subjects with bone metastasis

Percent subjects with brain metastasis

Percent subjects with lung metastasis

Percent subjects with other metastatic organs
Percent or NR if not mentioned specifically or clearly in the trial

Percent or NR if not mentioned specifically or clearly in the trial

Percent or NR if not mentioned specifically or clearly in the trial

Percent or NR if not mentioned specifically or clearly in the trial

Percent or NR if not mentioned specifically or clearly in the trial

Percent or NR if not mentioned specifically or clearly in the trial

Percent or NR if not mentioned specifically or clearly in the trial

Percent or NR if not mentioned specifically or clearly in the trial

Percent or NR if not mentioned specifically or clearly in the trial

Percent or NR if not mentioned specifically or clearly in the trial

Percent or NR if not mentioned specifically or clearly in the trial

Percent or NR if not mentioned specifically or clearly in the trial

Percent or NR if not mentioned specifically or clearly in the trial

Percent or NR if not mentioned specifically or clearly in the trial

Percent or NR if not mentioned specifically or clearly in the trial

Percent or NR if not mentioned specifically or clearly in the trial

Percent or NR if not mentioned specifically or clearly in the trial

Percent or NR if not mentioned specifically or clearly in the trial

NR if not mentioned specifically or clearly in the trial

Percent subjects with two metastatic organs or sites involved
Percent or NR if not mentioned specifically or clearly in the trial

Percent or NR if not mentioned specifically or clearly in the trial

Percent or NR if not mentioned specifically or clearly in the trial

Percent or NR if not mentioned specifically or clearly in the trial

Percent or NR if not mentioned specifically or clearly in the trial

Percent or NR if not mentioned specifically or clearly in the trial 
Table 5 Variables for data extraction (Continued)

\begin{tabular}{|c|c|}
\hline \multicolumn{2}{|l|}{$\begin{array}{l}\text { Percent metastatic organ sites } \\
2\end{array}$} \\
\hline $\begin{array}{l}\text { Percent metastatic organ sites } \\
>3\end{array}$ & $\begin{array}{l}\text { Percent subjects with three or more metastatic } \\
\text { involved }\end{array}$ \\
\hline $\begin{array}{l}\text { Percent hemoglobin }<11.5 \mathrm{~g} / \\
\mathrm{dl}\end{array}$ & Percent subjects with baseline hemoglobin I \\
\hline $\begin{array}{l}\text { Patient demographic } \\
\text { comments }\end{array}$ & $\begin{array}{l}\text { Any pertinent demographic comments that are } \\
\text { other variables }\end{array}$ \\
\hline Percent previous surgery & $\begin{array}{l}\text { Subjects with previous treatment for NSCLC as } \\
\text { partial surgery. Procedures include wedge resec } \\
\text { of part of a lobe), segmentectomy (removal of } \\
\text { division of a particular lobe of the lung), lobect } \\
\text { bilobectomy (two lobes), or pneumonectomy }\end{array}$ \\
\hline Percent previous radiotherapy & $\begin{array}{l}\text { Percent subjects with previous radiotherapy as } \\
\text { NSCLC }\end{array}$ \\
\hline $\begin{array}{l}\text { Percent previous } \\
\text { chemotherapy }\end{array}$ & $\begin{array}{l}\text { Percent subjects with previous chemotherapy } \\
\text { NSCLC }\end{array}$ \\
\hline \multicolumn{2}{|l|}{ Comorbidities } \\
\hline \multicolumn{2}{|l|}{ Percent comorbidities } \\
\hline \multicolumn{2}{|l|}{ Percent previous platinum } \\
\hline $\begin{array}{l}\text { Percent no previous } \\
\text { treatment }\end{array}$ & Percent subjects with no treatment for NSCLC \\
\hline revious treatment comments & ents regarding the previous treatm \\
\hline
\end{tabular}

Percent metastatic organ sites

Percent metastatic organ sites $>3$

Percent hemoglobin $<11.5 \mathrm{~g} /$

Patient demographic comments

Any pertinent demographic comments that are not dealt by

Subjects with previous treatment for NSCLC as complete or partial surgery. Procedures include wedge resection (removal division of a particular lobe of the lung), lobectomy (one lobe), ole lung) Percent subjects with previous chemotherapy as treatment for chemotherapy

Comorbidities
Percent or NR if not mentioned specifically or clearly in the trial

Percent or NR if not mentioned specifically or clearly in the trial

Percent or NR if not mentioned specifically or clearly in the trial

Any comment that may be relevant to the understanding of the demographic characteristics of the patient population

Percent or NR if not mentioned specifically or clearly in the trial

Percent or NR if not mentioned specifically or clearly in the trial

Percent or NR if not mentioned specifically or clearly in the trial

At baseline and by treatment arm

At baseline and by treatment arm;\% or NR

Percent or NR if not mentioned specifically or clearly in the trial

Any comment that may be relevant to the understanding of the previous NSCLC treatment in this record, NA if no comments

\section{Data entry standards}

Repository

Description

NSCLC drug, e.g., cisplatin, docetaxel point

Primary NSCLC dose

Randomized daily dose at time of outcome. Please note that this is the dose the patients were receiving when the observation is made (not the first randomized dose). If the treatment is switched at the time of observation, record the prior treatment the patients were getting just before the observation was made

Primary NSCLC dose achieved

Average daily dose during assessment period or for the total treatment period

Primary NSCLC dose unit

Unit of total daily or average dose achieved

Average daily dose achieved. Specifically useful for dose titration and crossover trials, NA for the fixed dose trials as both dose achieved and total daily dose do not vary

Unit, NR if not reported

e.g., d1, d8

Primary Rx days of

administration

Primary therapy duration and

route of administration

Primary NSCLC Rx cycle

duration

Primary NSCLC Rx number of cycles

Primary NSCLC formulation

Special treatment formulation

Only specialized formulations like IR, CR, SR

Indicates whether the observation refers to the first, continuing or last dose of the therapy
Start $=$ first dose starts on at this time, continuing $=$ treatment is continuing at this time, end = 
Table 5 Variables for data extraction (Continued)

\begin{tabular}{|c|c|c|}
\hline & & $\begin{array}{l}\text { treatment has been discontinued at this time (last } \\
\text { dose) }\end{array}$ \\
\hline $\begin{array}{l}\text { Primary NSCLC dose } \\
\text { comments }\end{array}$ & Comment regarding the dosing of primary NSCLC treatment & $\begin{array}{l}\text { Any comment that may be relevant to the } \\
\text { understanding the dosing of the primary treatment } \\
\text { in this record, NA if no comments }\end{array}$ \\
\hline Combo NSCLC therapy & $\begin{array}{l}\text { Name of secondary NSCLC therapy used in this arm in } \\
\text { addition to the primary treatment at that time point }\end{array}$ & $\begin{array}{l}\text { NSCLC drug, e.g., PTH NA if no secondary NSCLC } \\
\text { therapy }\end{array}$ \\
\hline Combo NSCLC dose & $\begin{array}{l}\text { Randomized daily dose of the secondary NSCLC therapy at } \\
\text { time of outcome. Refer to the dose description of primary } \\
\text { NSCLC dose }\end{array}$ & $\begin{array}{l}\text { Total daily dose at the time of observation, NR if } \\
\text { not reported and NA if no secondary NSCLC } \\
\text { therapy }\end{array}$ \\
\hline $\begin{array}{l}\text { Combination NSCLC dose } \\
\text { achieved }\end{array}$ & $\begin{array}{l}\text { Average daily dose of the secondary NSCLC therapy during } \\
\text { assessment period or for the total treatment period }\end{array}$ & $\begin{array}{l}\text { Average daily dose achieved. Specifically useful for } \\
\text { dose titration and crossover trials, NA for the fixed } \\
\text { dose trials as both dose achieved and total daily } \\
\text { dose do not vary }\end{array}$ \\
\hline Combination NSCLC dose unit & $\begin{array}{l}\text { Unit of total daily or average dose achieved for the secondary } \\
\text { NSCLC therapy }\end{array}$ & $\begin{array}{l}\text { Unit, NR if not reported or NA if no secondary } \\
\text { NSCLC therapy }\end{array}$ \\
\hline Combination NSCLC dose reg & Frequency of secondary NSCLC therapy being administered & QD, BID, etc., NA if no secondary NSCLC therapy \\
\hline \multicolumn{3}{|l|}{$\begin{array}{l}\text { Combination NSCLC dose } \\
\text { freq/cycle }\end{array}$} \\
\hline $\begin{array}{l}\text { Combination Rx days of } \\
\text { administration }\end{array}$ & & e.g., d1, d8 \\
\hline $\begin{array}{l}\text { Combination } R x \text { duration and } \\
\text { route of administration }\end{array}$ & & e.g., 10 min i.v. infusion \\
\hline \multicolumn{3}{|l|}{$\begin{array}{l}\text { Combination NSCLC Rx cycle } \\
\text { duration }\end{array}$} \\
\hline \multicolumn{3}{|l|}{$\begin{array}{l}\text { Combination NSCLC Rx } \\
\text { number of cycles }\end{array}$} \\
\hline $\begin{array}{l}\text { Combination NSCLC dose } \\
\text { comment }\end{array}$ & Comment regarding the dosing of secondary NSCLC therapy & $\begin{array}{l}\text { Any comment that may be relevant to the } \\
\text { understanding the dosing of the secondary } \\
\text { treatment in this record, NA if no comments or no } \\
\text { secondary NSCLC therapy }\end{array}$ \\
\hline Concomitant medications & & Baseline or by treatment arm \\
\hline \multicolumn{3}{|l|}{ Radiation therapy information } \\
\hline Repository & Description & Data entry standards \\
\hline
\end{tabular}

Radiation therapy type

Radiation therapy comments

Assessment characterization

Repository

\section{Description}

Common name for assessment that this record refers to, e.g., PANSS

Assessment short form

Code for the assessment

Assessment comment

Assessment location

Assessment category

Assessment Stat parameter

Stat population

Missing data treatment
Any comment that describes the nature of the assessment

Location from where the assessment value is taken or extracted from the manuscript

Describes what the assessment value represented is, whether it Absolute, CFB, PCFB, Frac, or Count is absolute, change from baseline (CFB), percent change from baseline (PCFB), or fraction of randomized patients with the event, count in case of tender or swollen joint counts

The summary parameter of the assessment value

Statistical population for which the efficacy/safety analyses were done and value reported

Method used for handling with missing observations in computing the summary parameter

\section{Data entry standards}

As in the assessments and conventions sheet

As in the assessments and conventions sheet

e.g., plasma glucose level, NA if no comments

Table number, figure number, page number

Mean, median, percent, NR if not reported

ITT, OC, completers, randomized, PPP (per protocol population: define), NR if not reported

LOCF (last observation carried forward), none, NR if not reported and NA in case of completers 
Table 5 Variables for data extraction (Continued)

\begin{tabular}{|c|c|c|}
\hline Scale lower limit & Scale lower limit & $\begin{array}{l}\text { The lower limit of the scale for the assessment, NA } \\
\text { if not applicable }\end{array}$ \\
\hline Scale upper limit & Scale upper limit & $\begin{array}{l}\text { The upper limit of the scale for the assessment, NA } \\
\text { if not applicable }\end{array}$ \\
\hline $\begin{array}{l}\text { Assessment categories or } \\
\text { words }\end{array}$ & Scale category description & $\begin{array}{l}\text { Category that is associated with each point of the } \\
\text { scale }\end{array}$ \\
\hline Total levels & Total categories/points in the scale & $\begin{array}{l}\text { The total number of categories associated with } \\
\text { each point of the scale, e.g., } 0 \text { to } 4 \text { point scale }\end{array}$ \\
\hline Total symptoms & Total symptoms in the scale & $\begin{array}{l}\text { The total number of symptoms associated with the } \\
\text { respective assessment, NA if not applicable }\end{array}$ \\
\hline Total score lower limit & $\begin{array}{l}\text { Lower limit of the scale, this is calculated as the number of } \\
\text { levels multiplied with the lowest possible scale }\end{array}$ & Integer value, NA if not applicable \\
\hline Total score upper limit & $\begin{array}{l}\text { Upper limit of the scale, this is calculated as the number of } \\
\text { levels multiplied with the highest possible scale }\end{array}$ & Integer value, NA if not applicable \\
\hline Assessment level & $\begin{array}{l}\text { For ordered categorical data "scales." Indicates which level in } \\
\text { the categorical scale the assessment is referring to }\end{array}$ & $\begin{array}{l}\text { Integer level from } 1 \text { to number of levels, if fractional } \\
\text { responder type, enter responder threshold value, } \\
\text { eg., } \geq 5 \% \text { weight loss from baseline for total body } \\
\text { weight assessment, etc., NA if not applicable }\end{array}$ \\
\hline
\end{tabular}

PROs

Scale, mean value, SD by group, time point

Time, assessment, and baseline value information

\section{Repository}

Assessment visit

Assessment time reported

Assessment time unit reported

Assessment time range reported

Assessment time normalized

Assessment time unit normalized

Assessment value

Assessment unit

Assessment SE

Assessment SD

Assessment $\mathrm{Cl}$ type

Assessment lower $\mathrm{Cl}$

Assessment upper $\mathrm{Cl}$

Assessment value normalized

Assessment value unit norm

Assessment SE normalized

Assessment SD normalized

\section{Description}

Clinical visit at which the assessment is done

Time at which the assessment is done during the study and as reported in the manuscript

Unit for reported assessment time

In case if the assessment values are average over a time interval

Normalized time in days at which the assessment is done during the study and as reported in the manuscript

Unit for standard assessment time

Assessment value reported at that time point

Assessment unit as reported

SE of reported assessment value

SD of reported assessment value

Assessment value converted into normalized assessment units

Normalized assessment value units

Standard error of normalized assessment value

Standard deviation of normalized assessment value

\section{Data entry standards}

Visit 1 (usually baseline) is the first visit in the active phase. Lead in visits start at -1 and count backwards, NR if not reported

Visit 1 = baseline = time 0 and the lead in assessment time starts at -1 and count backwards

Time unit as reported

e.g., weeks 2 through 28 enter $2-28$

The normalized time value using the normalized unit as days, e.g., 4 weeks $=28$ days

Days is the standard unit

Assessment value as reported

Assessment unit as reported, NA if not applicable

SE as reported, NR if not reported

SD as reported, NR if not reported
Still insert value here, report if normalized units are the same as the reported units

See assessments and conventions sheet for normalized assessment standard

SE in the same units as normalized assessment, may need to be calculated from SD and $N$; if not provided, NA

SD in the same units as normalized assessment, may need to be calculated from SE and $N$; if not provided, NA 
Table 5 Variables for data extraction (Continued)

Assessment Cl type

normalized

Assessment lower $\mathrm{Cl}$

normalized

Assessment upper Cl

normalized

Assessment number

Number of patients assessed at that time point and the value derived

Assessment value comment

Comment pertaining to the assessment value that cannot be dealt by other variables

Hazard ratio

Baseline visit

Baseline time

Baseline time unit

Baseline time normalized

Baseline time unit normalized

Baseline value

Baseline value unit

Baseline SE

Baseline SD

Baseline $\mathrm{Cl}$ type

Baseline lower Cl

Baseline upper $\mathrm{Cl}$

Baseline value normalized

Baseline value unit normalized

Baseline SE normalized

Baseline SD normalized

Baseline Cl type normalized

Baseline lower $\mathrm{Cl}$ normalized

Baseline upper $\mathrm{Cl}$ normalized

Baseline N

Baseline value comment

Reference specifications

Repository

Ref code

Protocol or trial number

Date modified

Modified by
95\% confidence intervals, progression-free survival, and overall survival_adjusted and unadjusted

Clinical visit at which the baseline assessment is done

Time at which the baseline assessment is done

Unit for reported baseline time

Normalized time in days at which the baseline is done during the study and as reported in the manuscript

Unit for standard baseline time

Absolute baseline value for that assessment

Assessment unit as reported

SE of the absolute baseline value

SD of the absolute baseline value

Baseline value converted into normalized baseline units

Normalized baseline value units

Standard error of normalized baseline value

Standard deviation of normalized baseline value

Number of patients from which the baseline value is derived

Comment pertaining to the baseline value that cannot be dealt by other variables

\section{Description}

Numerical code assigned for the literature citation. Maps the record to the assessment details

Protocol ID or the number of the trial report

Date of initial entry or subsequent modification of the data point

Initials of curator
Integer value, but for responders and dropouts, this value is calculated from the percentages reported in the trial

e.g., the assessment value is the mean of last 7 days of before each clinical visit, etc.

Visit 1 = baseline = time $0, N R$ if not reported

Visit $1=$ baseline $=$ time 0

Time unit as reported

The normalized time value using the normalized unit as days, e.g., -4 weeks $=-28$ days

Days is the standard unit

Absolute baseline value

Assessment unit as reported, NA if not applicable

SE as reported, NR if not reported

SD as reported, NR if not reported

Still insert value here report if normalized units are the same as the reported units

See assessments and conventions sheet for normalized assessment standard

SE in the same units as normalized baseline, may need to be calculated from SD and $N$; if not provided, NA

SD in the same units as normalized baseline, may need to be calculated from SE and $N$; if not provided, NA

Integer

e.g., the baseline value is the mean of last 7 days of the run in period

\section{Data entry standards}

Integer

As reported, NA if not applicable

mmddyy format 
Table 5 Variables for data extraction (Continued)

\begin{tabular}{|c|c|c|}
\hline Modification comment & Any comment that is relevant to modification by the curator & $\begin{array}{l}\text { Initial entry if new record, brief statement of change } \\
\text { (s) }\end{array}$ \\
\hline Copyright status & Provided by the client or procured by the service provider & $\begin{array}{l}\text { Client provided or yes in case the manuscript is } \\
\text { procured by the service provider }\end{array}$ \\
\hline Author & Authors of publication & As reported \\
\hline Journal & Journal name & $\begin{array}{l}\text { Standard abbreviated forms can be used, generally } \\
\text { as in the PubMed }\end{array}$ \\
\hline Publication year & Year of the publication & Integer \\
\hline Title & Title of the study & \\
\hline Volume & Volume number of the publication & e.g., 180 \\
\hline Pages & Page numbers of the publication & e.g., $1-24$ \\
\hline Trial name alias & Trial name that trial is commonly referred to & NR if not reported \\
\hline Inclusion description & Provide description of inclusion criteria & $\begin{array}{l}\text { Can be cut and paste from PDF, can be placed in } \\
\text { an attached note }\end{array}$ \\
\hline Exclusion description & Provide description of exclusion criteria & $\begin{array}{l}\text { Can be cut and paste from PDF, can be placed in } \\
\text { an attached note }\end{array}$ \\
\hline Study design & Brief description of the study design & $\begin{array}{l}\text { Parallel-fixed arm, dose escalation, effect titration, } \\
\text { crossover, etc. }\end{array}$ \\
\hline Location of the trial & Geographical location where the study is conducted & Primary nationalities list \\
\hline Number of countries & Number of countries the study is conducted & Integer \\
\hline Number of centers & Number of centers the study is conducted & Integer \\
\hline Trial start date & Date when the trial started & mmddyy format \\
\hline Trial end date & Date when the trial completed & mmddyy format \\
\hline $\begin{array}{l}\text { Placebo-controlled or active } \\
\text { comparator }\end{array}$ & Was there a control group and was it placebo & PBO control/active comparator \\
\hline Active comparator therapy & $\begin{array}{l}\text { If this was an active comparator trial what was the comparator } \\
\text { therapy }\end{array}$ & e.g., PTH \\
\hline $\begin{array}{l}\text { Percent randomized to } \\
\text { placebo }\end{array}$ & Percent of subjects in the trial who are randomized to placebo & Integer \\
\hline Add-on/washout study & $\begin{array}{l}\text { Was the study drug added on to standardized background } R x \text {, } \\
\text { was background Rx washed out prior to starting primary } R x \text {, or } \\
\text { was standardized background therapy withdrawn once primary } \\
\text { RX started }\end{array}$ & Add-On, Washout, Replacement, None \\
\hline Study blind & Was the trial blinded for the treatment phase & Yes, double blind \\
\hline Number of arms & Number of treatment arms the patients are randomized to & Integer \\
\hline Arm description & Codes and description for arms & $0=$ placebo and others in sequence \\
\hline Dose descriptions & $\begin{array}{l}\text { Brief descriptions of the treatment drugs and the respective } \\
\text { doses along with regimens received }\end{array}$ & $0=$ placebo, 1 = metformin $10 \mathrm{mg} \mathrm{QW} \ldots$ \\
\hline Dose ranging within study & $\begin{array}{l}\text { Does the trial contain at least two primary treatment arms } \\
\text { where different dose strengths were administered }\end{array}$ & Yes, No. Placebo does not count as a dose strength \\
\hline Primary longitudinal data & $\begin{array}{l}\text { Were multiple time values reported for the primary assessment } \\
\text { endpoint }\end{array}$ & Yes, No. \\
\hline Active phase trial duration & What was the duration of the active phase of the trial & Time, units, i.e., 3 weeks \\
\hline Steady state effect achieved? & $\begin{array}{l}\text { Does it appear that effect stabilized over time for primary } \\
\text { endpoints }\end{array}$ & Yes, No. Not clear \\
\hline Was there a lead-in phase? & $\begin{array}{l}\text { Was there a standardized lead-in phase in the study other than } \\
\text { a simple screening visit }\end{array}$ & Yes, No \\
\hline Lead-in phase duration & If so, what was the duration & If yes, time, units, i.e., 6 months. If no, 0 \\
\hline Was there a follow-up phase? & $\begin{array}{l}\text { Was there a standardized follow-up phase that at least some } \\
\text { patients were enrolled in after the active phase ended }\end{array}$ & Yes, No \\
\hline
\end{tabular}


Table 5 Variables for data extraction (Continued)

\begin{tabular}{|c|c|c|}
\hline Duration of follow-up phase & If so, what was the duration & If yes, time, units, i.e., 6 months. If no, 0 \\
\hline Primary endpoint & $\begin{array}{l}\text { What is the primary outcome or assessment reported in the } \\
\text { trial }\end{array}$ & e.g., HBA1C \\
\hline \multicolumn{3}{|l|}{ Secondary endpoints } \\
\hline $\begin{array}{l}\text { Other efficacy endpoints } \\
\text { available }\end{array}$ & $\begin{array}{l}\text { List of the other secondary efficacy or biomarker outcomes } \\
\text { reported in the trial }\end{array}$ & e.g., HOMA \\
\hline Most frequent AEs (incidence) & List the most frequently reported $A E^{\prime} s$ & e.g., vomiting, nausea, headache, dizziness \\
\hline Adverse events & $\begin{array}{l}\text { Grade, } \%, n \text { by group, treatments for AEs, hospitalizations } \\
\text { secondary to AEs and overall, ICU admissions secondary to AEs } \\
\text { and overall }\end{array}$ & \\
\hline Median and mean if reported & $\begin{array}{l}\text { Progression-free survival and overall survival in months (TTPD, } \\
\text { TTTF) }\end{array}$ & \\
\hline Survival rates & Percent alive at $X$ months & \\
\hline Response rates & At what time? & \\
\hline Toxicity & Number of individuals experiencing toxicity/treatment group & \\
\hline
\end{tabular}

inconsistencies. Density plots of the posterior samples from models based on direct, indirect, and mixed evidence will be compared. In addition, the heterogeneity parameters (variance and standard deviation) and goodness of model fit measures (residual deviance and deviance information criterion (DIC), a Bayesian criterion for model comparison) between the direct and indirect models will be compared.

OS and PFS data will be analyzed using a log transformation of the HR and treating this as a continuous outcome. For studies with median time information, we will also use log transformation of the median time and treat this as a continuous outcome in sensitivity analyses. HRs are preferred summary statistics to median time per Michiels and colleagues [13], and hence, the analysis will utilize HR data for the primary outcome measure.

Ideally, the literature will provide values for log (HR) and the standard error (SE) for log (HR). If the SE for $\log (\mathrm{HR})$ is not available, an attempt will be made to estimate the missing value from the SE for median time, assuming an exponential distribution of survival time and $\log (\mathrm{HR})=-\log$ (median time ratio). Alternatively, an estimate of the SE for log (HR) will be made on the basis of the number of subjects with events as specified below:

1. "MedianTime" will be converted into log (median time);

2. The SE for log (median time) is estimated as (log (upper confidence limit) - log (lower confidence limit))/2/quantile (confidence level) if a treatment arm has non-missing value for all three variables;

3. If confidence limit is missing, then the number of subjects with events can be used to estimate the standard error for log (median time) as $1 / \operatorname{sqrt}(n)$ for a treatment arm.

Individual odds ratios and/or toxicity rates for each grade 3-4 toxicity from each study will be included, respectively, in an NMA using a Bayesian approach that ensures the preservation of randomization in the network. Odds ratios will be calculated for studies reporting toxicity rates. Prior to creating the odds ratios, we will ensure that similar versions of toxicity scaling criteria have been used. Data for analysis will be directly extracted from the text of the article or calculated from data in the text.

A network meta-analysis of $\mathrm{GC}+\mathrm{N}$ to all identified comparators will be conducted for health-related quality of life (HRQoL) measures (including EQ-5D and the Lung Cancer Symptom Scale (LCSS)) during and following therapy. The most common quality of life instruments as reported across studies will be analyzed. Initial analyses will be limited to those quality of life outcomes for which $\mathrm{GC}+\mathrm{N}$ data are available. For each identified measure, a standardized mean difference in quality of life outcomes from each study will be included. First, the number of trials per HRQoL instrument will be determined. If the number of trials per HRQoL instrument is 2 or more, then these data will be analyzed. For each instrument, data will be assessed according to the guidelines for that particular instrument and then pooled across studies to determine the standardized mean difference.

A meta-regression will be conducted using the key covariates of patient age and stage of disease (percent of patients with stage IV), as these variables have prognostic value in squamous NSCLC. Additional covariates may be identified following the literature review and will be considered for inclusion in post hoc analyses to control for potential bias. 


\section{Sensitivity analyses}

We anticipate that some studies will not report all relevant data. In order that such studies can still be included in the analysis, we may consider imputing missing data using established methods as appropriate [14]. If imputation is made, the Bayesian model as described above will be used as the primary analysis and will be compared with analyses including the imputed values. Sensitivity analyses may be conducted to examine the effect of this method using an approach proposed by Carpenter and colleagues [15], which entails imputing missing data under a missing at random assumption, and then reweighting the imputed data to allow for non-random selection. Sensitivity analyses as outlined for OS and PFS will also be conducted for HRQoL; however, the use of disparate HRQoL instruments or assessment time points may result in an inability to evaluate the study endpoint. Sensitivity analyses will be performed to assess the robustness of the findings. At a minimum, the following analyses will be conducted if there are at least three studies available for analysis:

1. Repeat the meta-analysis using a frequentist approach;

2. HR only (primary aim) versus HR or median time;

3. By geographical site of study enrollment;

a. e.g., Western versus Eastern hemispheres

b. e.g., Americas versus Europe versus Asia

4. Limit to patients with stage IV disease;

5. Direct comparisons only;

6. By excluding phase II trials;

7. By age-studies with a mean age over the age of 70 ;

8. Limiting the analysis to high-quality studies $(\geq 6)$ as determined by the PEDro scale;

9. Removing studies considered to be biased according to the Cochrane Risk of Bias Tool.

\section{Assessment of bias and study quality}

The risk of bias will be appraised using the Cochrane Risk of Bias Tool (www.cochrane-handbook.org). This tool was developed specifically to assess the internal validity of RCTs. It consists of the following seven criteria: 1) randomization generation, 2) allocation concealment, 3) blinding of outcome assessors, 4) blinding patients and personnel, 5) incomplete outcome data (i.e., withdrawals), 6) selective outcome reporting, and 7) other risks of bias. The final item will include fraudulent results, other methodological flaws in the RCTs, and the potential for bias.

To assess publication bias, the fail-safe $N$ will be calculated. If the number of unpublished trials that may invalidate the findings is less than five, it will be noted in the conclusions as a potential limitation of the findings. If the number of unpublished trials to invalidate the findings is five or greater, it will be noted in the results. Furthermore, funnel plot analyses will also be conducted to provide a visual representation demonstrating where unpublished data may exist. This is planned to help guide the interpretation of the study findings and the direction of bias.

Quality of selected trials for inclusion in the review will be assessed. The PEDro quality scale, an 11-item scale designed for rating the methodological quality of randomized controlled trials [16], will be used to evaluate the quality of selected trials. Here the two reviewers will independently assess studies for methodological validity prior to inclusion. Identified studies that meet the inclusion criteria will then be grouped according to the class of statin used in the trial. High quality scores will be defined as a PEDro score $\geq 6$ and low quality scores will be defined as a PEDro score $<6$.

Missing data are expected in the majority of data fields collected in this meta-analysis. In cases of missing data, heterogeneity will be tested on all outcome variables to ensure that studies are comparable. Forest plots will be created for OS, PFS, toxicity, and quality of life endpoints. In the case of non-overlapping confidence intervals, the research team will discuss the need for post hoc subgroup analyses.

\section{Discussion}

The study design for this systematic review and metaanalysis is presented here to follow PRISMA standards. Industry-sponsored or industry-led studies are increasingly under scrutiny regarding transparency and risk of bias [17]. This study protocol has been designed prior to any knowledge of the study data or outcomes from existing published literature and is being disseminated in an attempt to provide the scientific community with the ability to evaluate the methods and plans of our study before it is conducted. The study protocol has been designed to meet PRISMA standards $[18,19]$ and is being disclosed so that our methods can be retrieved and evaluated against the final analyses and interpretation of findings.

While it is almost impossible to fully anticipate the limitations of the data once they are obtained, this study has been designed in an attempt to pre-specify all primary analyses and sensitivity analyses to demonstrate the stability in results that may be discovered. However, it is possible that there will not be sufficient data to achieve all the prespecified study aims or to complete all planned analyses. There are also possible limitations in the network connections. Unlike patients diagnosed with lung cancers of nonsquamous histology, those with squamous NSCLC have not benefited from the same depth and breadth of research conducted to identify optimal treatment strategies. Therefore, via our search criteria, we are casting a wide net in the hopes of finding studies that not only investigate, but also report, outcomes for this histological subgroup. 
Our ultimate goal is to provide reliable and trustworthy data regarding the comparative efficacy of necitumumab against other possible options for care so that decision makers can come to their own conclusions regarding the value of this molecule currently in development.

\section{Competing interests}

All study authors disclose that they are employees of Eli Lilly and Company.

\section{Authors' contributions}

AD participated in the study design, development of the study protocol, drafting of the analysis plan, and writing of the manuscript and will be responsible for data and eligibility review. JB conceived of the study design, review of the study protocol, and substantive input to the manuscript. FN developed the study protocol analysis plan and will be responsible for final analyses. LZ developed the study protocol analysis plan and will be responsible for final analyses. ZC developed the study protocol analysis plan and will be responsible for final analyses. SA will be responsible for data and eligibility review. LB and JT conceived of the study design and development of the study protocol. LH conceived of the study design, development of the study protocol, writing of the manuscript, and drafting of the analysis plan and will be responsible for data and eligibility review. All authors reviewed and approved the final version of the manuscript.

\section{Acknowledgements}

This study was funded by Eli Lilly and Company.

\section{Author details}

'Eli Lilly and Company, Indianapolis, IN, USA. ${ }^{2}$ Eli Lilly and Company, Erl Wood Manor, Windlesham, Surrey, UK.

Received: 23 April 2014 Accepted: 4 September 2014

Published: 16 September 2014

\section{References}

1. ALA: Lung Cancer Fact Sheet - American Lung Association. 2013 [http://www.lung.org/lung-disease/lung-cancer/resources/facts-figures/ lung-cancer-fact-sheet.html]

2. CancerCare: Lung Cancer 101. 2013 [http://www.lungcancer.org/find_ information/publications/163-lung_cancer_101/268-types_and_staging]

3. SEER: "Cancer Statistics." Cancer of the Lung and Bronchus. 2013 [http://seer.cancer.gov/statfacts/html/lungb.html]

4. Scagliotti G, Hanna N, Fossella F, Sugarman K, Blatter J, Peterson P, Simms L, Shepherd FA: The differential efficacy of pemetrexed according to NSCLC histology: a review of two phase III studies. Oncologist 2009, 14(3):253-263.

5. Johnson DH, Fehrenbacher L, Novotny WF, Herbst RS, Nemunaitis JJ, Jablons DM, Langer CJ, DeVore RF, Gaudreault J, Damico LA, Holmgren E, Kabbinavar F: Randomized phase II trial comparing bevacizumab plus carboplatin and paclitaxel with carboplatin and paclitaxel alone in previously untreated locally advanced or metastatic non-small-cell lung cancer. J Clin Oncol 2004, 22(11):2184-2191.

6. AstraZeneca: Iressa. Gefinitib. 2014 [http://www.iressa.com]

7. Genentech: Erlotinib Tablets. 2013 [http://www.tarceva.com]

8. Gahr S, Stoehr R, Geissinger E, Ficker JH, Brueckl WM, Gschwendtner A, Gattenloehner S, Fuchs FS, Rieker RJ, Hartmann A, Ruemmele P, Dietmaier W: EGFR mutational status in a large series of Caucasian European NSCLC patients: data from daily practice. Br J Cancer 2013, 109(7):1821-1828.

9. Howlader N, Noone AM, Krapcho M, Garshell J, Neyman N, Altekruse SF, Kosary CL, Yu M, Ruhl J, Tatalovich Z, Cho H, Mariotto A, Lewis DR, Chen HS, Feuer EJ, Cronin KA: SEER Cancer Statistics Review, 1975-2010. Bethesda: N.C. Institute; 2013.

10. Shen W, Zhu B, Han B, Natanegara F: Bayesian Network Meta-Analysis for Health Technology Assessment and Evaluation for Investigative Treatment. In ICSA/ISBS Joint Statistical Conference: 9-12 June 2013. Washington, DC: 2013.

11. Parmar MK, Torri V, Stewart L: Extracting summary statistics to perform meta-analyses of the published literature for survival endpoints. Stat Med 1998, 17(24):2815-2834.

12. Dias S, Welton NJ, Caldwell DM, Ades AE: Checking consistency in mixed treatment comparison meta-analysis. Stat Med 2010, 29(7-8):932-944.
13. Michiels S, Piedbois P, Burdett S, Syz N, Stewart L, Pignon JP: Meta-analysis when only the median survival times are known: a comparison with individual patient data results. Int I Technol Assess Health Care 2005, 21(1):119-125.

14. Littell JH, Pillai V: Systematic Reviews and Meta-Analysis. New York: Oxford University Press; 2008.

15. Carpenter J, Rucker G, Schwarzer G: Assessing the sensitivity of meta-analysis to selection bias: a multiple imputation approach. Biometrics 2011, 67(3):1066-1072.

16. de Morton NA: The PEDro scale is a valid measure of the methodological quality of clinical trials: a demographic study. Aust J Physiother 2009, 55(2):129-133.

17. Lundh A, Sismondo S, Lexchin J, Busuioc OA, Bero L: Industry sponsorship and research outcome. Cochrane Database Syst Rev 2012, 12, MR000033.

18. Liberati A, Altman DG, Teztlaff J, Mulrow C, Gøtszche PC, loannidis JPA, Clarke M, Devereaux PJ, Kleijnen J, Moher D: The PRISMA statement for reporting systematic reviews and meta-analyses of studies that evaluate healthcare interventions: explanation and elaboration. BMJ 2009, 339:b2700.

19. Moher D, Liberati A, Teztlaff J, Altman DG: Preferred reporting items for systematic reviews and meta-analyses: the PRISMA statement. BMJ 2009, 339:b2535.

doi:10.1186/2046-4053-3-102

Cite this article as: DeLozier et al: Study protocol: systematic review and meta-analysis of randomized controlled trials in first-line treatment of squamous non-small cell lung cancer. Systematic Reviews 2014 3:102.

\section{Submit your next manuscript to BioMed Central and take full advantage of:}

- Convenient online submission

- Thorough peer review

- No space constraints or color figure charges

- Immediate publication on acceptance

- Inclusion in PubMed, CAS, Scopus and Google Scholar

- Research which is freely available for redistribution 